\title{
ASSESSING CROP MONITORING POTENTIAL OF SENTINEL-2 IN A SPATIO-TEMPORAL SCALE
}

\author{
Parmita Ghosh $^{1, *}$, Dipankar Mandal ${ }^{1}$, Avik Bhattacharya ${ }^{1}$, Manoj Kumar Nanda ${ }^{2}$, Soumen Bera ${ }^{3}$ \\ ${ }^{1}$ Microwave Remote Sensing Lab, Centre of Studies in Resources Engineering, \\ Indian Institute of Technology Bombay, Mumbai, 400076 INDIA \\ paramita.january841@gmail.com; dipankar_mandal@iitb.ac.in; avikb@csre.iitb.ac.in \\ 2 Dept. of Agricultural Meteorology and Physics, Bidhan Chandra Krishi Viswavidyalaya, \\ Mohanpur, West Bengal, 741252 INDIA- mknandabckv@rediffmail.com \\ ${ }^{3}$ College of Agriculture, Bidhan Chandra Krishi Viswavidyalaya, \\ Bardhhaman, West Bengal, 713101 INDIA - soumen.bckv@gmail.com
}

Commission V, SS: Natural Resources Management

KEY WORDS: Crop Monitoring, Sentinel-2, Spatio-Temporal Analysis, NDVI, Green Normalized Difference Vegetation Index (GNDVI), Normalized Difference Index 45 (NDI45)

\begin{abstract}
:
Spatio-temporal variability of crop growth descriptors is of prime importance for crop risk assessment and yield gap analysis. The incorporation of three bands (viz., B5, B6, B7) in 'red-edge' position (i.e., $705 \mathrm{~nm}, 740 \mathrm{~nm}, 783 \mathrm{~nm}$ ) in Sentinel-2 with 10-20 m spatial resolution images with five days revisit period have unfolded opportunity for meticulous crop monitoring. In the present study, the potential of Sentinel-2 have been appraised for monitoring phenological stages of potato over Bardhaman district in the state of West Bengal, India. Due to the competency of Vegetation indices (VI) to evaluate the status of crop growth; we have used the Normalized Difference Vegetation Index (NDVI), the Green Normalized Difference Vegetation Index (GNDVI), and the Normalized Difference Index45 (NDI45) for crop monitoring. Time series analysis of the VIs exhibited increasing trend as the crop started approaching maturity and attained a maximum value during the tuber development stage and started decreasing as the crop advances to senescence. Inter-field variability of VIs highlighted the need of crop monitoring at high spatial resolution. Among the three vegetation indices, the GNDVI ( $\mathrm{r}=0.636)$, NDVI ( $\mathrm{r}=0.620)$ had the highest correlation with biomass and Plant Area Index (PAI), respectively. NDI45 had comparatively a lower correlation ( $\mathrm{r}=0.572$ and 0.585 for PAI and biomass, respectively) with both parameters as compared to other two indices. It is interesting to note that the use of Sentinel-2 Green band (B3) instead of the Red band (B4) in GNDVI resulted in $2.5 \%$ increase of correlation with biomass. However, the improvement in correlations between NDI45 with crop biophysical parameters is not apparent in this particular study with the inclusion of the Vegetation Red Edge band (B5) in VI. Nevertheless, the strong correlation of VIs with biomass and PAI asserted proficiency of Sentinel-2 for crop monitoring and potential for crop biophysical parameter retrieval with optimum accuracy.
\end{abstract}

\section{INTRODUCTION}

Agriculture plays a crucial role in Indian socio-economy. Thus it is essential to monitor utilization of agricultural resources and crop growth spatially. Spatial variability in the 15 agroclimatic zones of India is quite apparent which experience different weather, soil conditions, water quality, availability of farm inputs (Venkateswarlu et al. 1996). In addition, due to small land holding per capita, high spatio-temporal variability exists in cropping pattern in India (Hazra 2001; Manjunatha et al. 2013). Hence, it it utmost important to monitor crop persistently in a fine spatio-temporal scale to prevent crop loss due to disease, water stress and natural disaster. Subsequently, an unambiguous crop monitoring is important in the context of policy making towards assurance of food security.

Remote sensing has the potential to provide accurate crop condition information across larger spatial extent. Furthermore, Eath Observation (EO) data has proven the ability to deliver crop growth condition information in a timely manner within a crop season (Hansen and Loveland, 2012, Atzberger 2013). Furthermore, according to the framework of the Group on Earth Obser-

${ }^{*}$ Corresponding author: Parmita Ghosh vations Global Agricultural Monitoring (GEOGLAM) Initiative and the Committee on Earth Observation Satellites (CEOS), a high temporal resolution data would be required in order to monitor critical growth stages of crop reasonably (Whitcraft et al. 2015). In this context, recently launched Sentinel-2 constellation with twin satellite (S-2A/B) in June 2015 and March 2017, respectively has provided unprecedent opportunities for agricultural monitoring (Defourny et al. 2018).

Sentinel-2 enables multiple operational reflectance measurements with a short revisit period (5 days) desired for vegetation monitoring. The combinations of several bands provide opportunities for improved characterization of crop traits (Frampton et al. 2013, Defourny et al. 2018). Especially, three spectral bands (705 nm, $740 \mathrm{~nm}, 783 \mathrm{~nm})$ in 'Red-Edge' region have been incorporated for precise monitoring of vegetation condition. High spatial resolution (10m and $20 \mathrm{~m}$ resolution products) of Sentinel2 make it a viable option for monitoring small agricultural fields.

In optical remote sensing of vegetation, vegetation indices are often used as descriptors of crop health status. These indices provide an insight of crop dynamics over the period of time (Baret and Guyot, 1991, Haboudane et al. 2002, Ceccato et al. 2002). These indices were derived on the basis of spectral signature of 
vegetation, because spectral signature act as a proxy of leaf pigments and structure. The very first index Simple Ratio (SR) was derived by Jordan (1969) as a ratio of reflectance at Near infra-red (NIR) band to red band for leaf area index (LAI) measurement. The index was developed with a logic that since absorption is high in red band as compare to NIR band. Thus presence of more leaf will result in higher SR.

The most popular index Normalized Difference Vegetation Index (NDVI) introduced by Rouse et al. (1974), was a modified version of SR which was designed for above ground biomass. In NDVI formula, ratio of difference between radiance at Red band and NIR band to sum of radiance between the same was considered to make the index more generalized. This index was considered to abolish the effect of atmospheric attenuation and seasonal sun angle variations. Gitelson et al. (1996) had proposed Green Normalized Difference Vegetation Index (GNDVI) based on their finding that the Green band $(520 \mathrm{~nm}-630 \mathrm{~nm})$ is sensitive to the whole range of leaf chlorophyll concentration (0.3$45 \mu \mathrm{gcm}^{-2}$ ); whereas Red band is not sensitive to $3-5 \mu \mathrm{gcm}^{-2}$ chlorophyll concentration. It was reported that Red band is not sensitive for yellow green to green leaves. In the same experiment, it was reported that chlorophyll concentration had higher correlation with inverse of the reflectance in the Green band as compared to Red band. It was proclaimed that the sensitivity of GNDVI is five times higher for stressed and senescent condition of vegetation as compared to NDVI.

Introduction of measurement bands in red-edge position in Sentinel-2 has motivated to find out optimum normalized vegetation index which would be robust for Leaf Area Index (LAI) and chlorophyll estimation. With a pre-launch experiment, Delegido et al. (2011) proposed a new optimum index as Normalized Difference Index 45 (NDI45). The experiment was conducted with $\sim 300$ data of seven crop types with LAI value ranges in between $0-7$ and reported an improved correlation $(r=0.908)$ of NDI45 with LAI. Thus, it provides an opportunity to get a better accuracy in LAI estimation with NDI45 derived from Sentinel 2 images as compared to NDVI. However, a competence of these vegetation indices derived from Sentinel-2 need to be investigated for monitoring crop growth within a crop season. In this present research, an comparative analysis of NDVI, GNDVI and NDI45 are assessed in a temporal as well as spatial scale for Sentinel-2 data acquired over agricultural area.

\section{MATERIALS AND METHODS}

\subsection{Study Area}

The test site is located in the Damodar River Basin of East Barddhaman district in the state of West Bengal, India, centred on the Barddhaman town $\left(23^{\circ} 18^{\prime} 39.43^{\prime \prime} \mathrm{N}\right.$ and $\left.88^{\circ} 11^{\prime} 04.58^{\prime \prime} \mathrm{E}\right)$ as shown in Figure 1] This area has a gentle slope and covers mostly new alluvium soil zone. The test site covers an area of $30 \times 30 \mathrm{~km}^{2}$ and is characterized by a predominantly agricultural area. Rice is the major crop, which is grown in two distinct seasons, monsoon (June-October) and summer (FebruaryMay) (Mandal et al. 2018). Beside the rice other major crops includes potato (early winter), mustard, sesame, and jute.

The present research addresses analysis with the winter season (December-March) crop Potato (Solanum tuberosum), which is having a wide plantation calendar extending from November to
December. Due to this plantation period variability and adaptation of several potato plant varieties, a spatial as well as temporal variability in crop growth is likely in this plain.

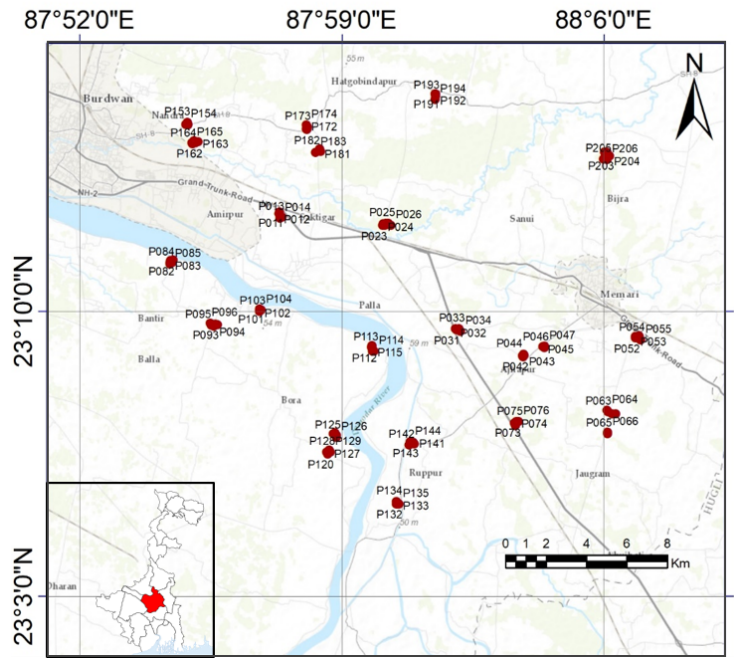

Figure 1. Location of sampling fields in study area.

\subsection{Sampling Strategy}

In-situ measurements were collected intensively between the period of of December 2017 to March 2018. During the campaign, $\sim 68$ fields were selected for sampling. The nominal size of each field was $\sim 60 \mathrm{~m} \times 60 \mathrm{~m}$. During these campaigns, in-situ measurements of crop biophysical parameters viz. biomass, Plant Area Index(PAI), plant height and soil moisture were collected at different phenological stages of potato. Above ground biomass was collected by destructive sampling. At each sample location, 10 plants(5 plants/row) were harvested from two consecutive rows. Plant area index (PAI) was measured by processing digital hemispherical photographs in CANEYE software (INRA. 2017). Soil moisture was measured in two locations within a field using Theta Probe. The detailed description of soil and vegetation sampling can be found in the campaign experimental plan (Mandal et al. 2017).

\subsection{Sentinel-2 Data and Image Processing}

Eight Sentinel-2 time series (December,2017- March,2018) images(Level 1C) were acquired over this study area. ESA Sentinel Application Platform (SNAP) toolbox was used for image processing. Atmospheric correction was done in Sen2Core. Spectral bands of Sentinel-2 have three different spatial resolutions $(10 \mathrm{~m}$, $20 \mathrm{~m}, 30 \mathrm{~m}$ ), so all the images were resampled at $20 \mathrm{~m}$ spatial resolution. Subsequently, images were Subset according to the boundary of study area. Three vegetation indices viz. NDVI, GNDVI, NDI45 were generated for tracking crop health condition in all the growth stages. Formulation of these VIs are shown in Table 1 Finally, the VIs for each sampling locations were calculated as the average of a 3 window centred on each location from the VI images for individual dates.

\section{RESULTS AND DISCUSSION}

This section includes the time series analysis of VIs and explained with different phenological stages of potato for several fields. Subsequently, the spatio-temporal images of VIs are analyzed. Finally, the correlation between Vis with PAI and biomass are assessed. 
Table 1. Vegetation indices with Sentinel-2 bands configurations

\begin{tabular}{|c|c|}
\hline Vegetation Index & Formula \\
\hline NDVI & $(\mathrm{B} 8-\mathrm{B} 4) /(\mathrm{B} 8+\mathrm{B} 4)$ \\
\hline GNDVI & $(\mathrm{B} 8-\mathrm{B} 3) /(\mathrm{B} 8+\mathrm{B} 3)$ \\
\hline NDI45 & $(\mathrm{B} 5-\mathrm{B} 4) /(\mathrm{B} 5+\mathrm{B} 4)$ \\
\hline
\end{tabular}

\subsection{Time Series Analysis of Vegetation Indices}

Time series trend of all three VIs derived from Sentinel-2 are given in Figure 2 3, 4 for the period December, 2017- March, 2018. The time series plots were generated for several sampling locations. It is evident from in-situ measurements that majority of the potato fields were planted during the end of the second week of December, 2017. Then it advanced from sprouting to leaf development during the first week of January, 2018 and main stem elongation started. Potato plants started developing tuber over the last week of January, 2018. Potatoes were fully developed and harvested during end of the February, 2018.

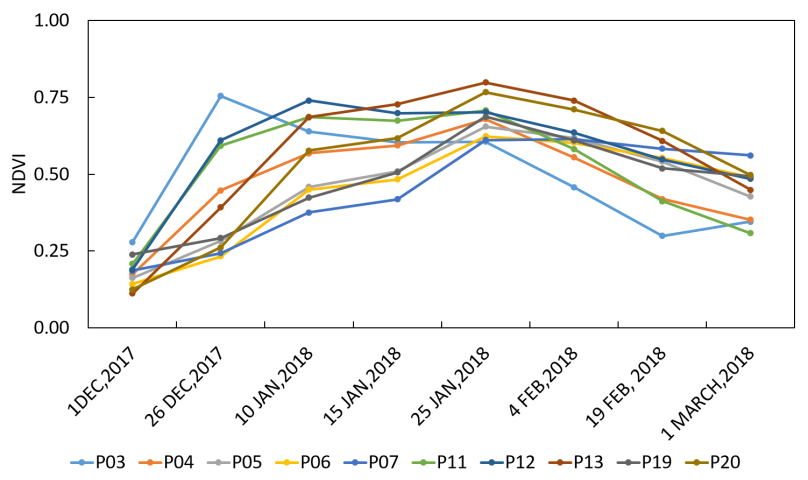

Figure 2. NDVI time series

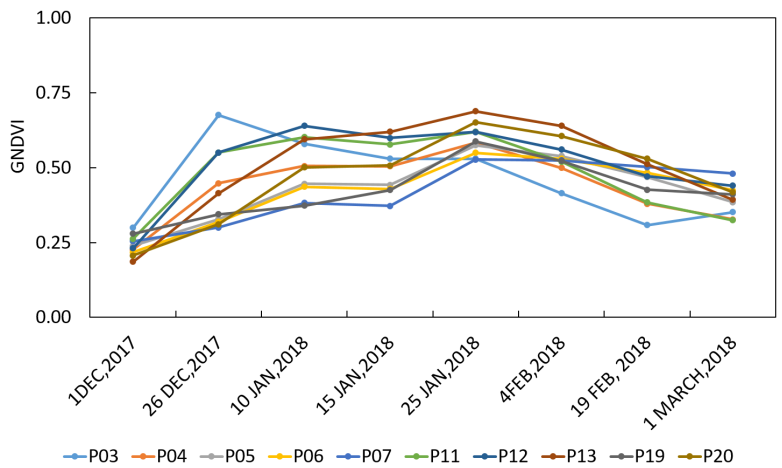

Figure 3. GNDVI time series

It is evident in Figure 2 that NDVI had low values $(<0.1)$ in 1 December, 2017. It is likely due to the soil contribution to the reflectance when there was no standing crop in fields. Sprouting was complete and plat started developing during the end of December, 2017 to the beginning of January, 2018. Value of VIs also started increasing during this period. An increasing trend was exhibited by VI from 26 December,2017 to 25 January, 2018 because potato plants developed tuber in this period. After 25 January, 2018 as potatoes were approaching fully developing stage, trend of NDVI were monotonically decreasing. On 19 February,

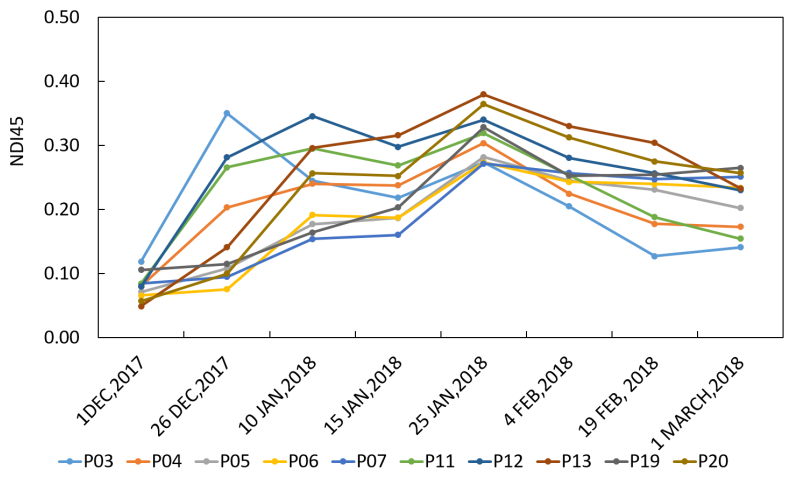

Figure 4. NDI45 time series

2018 VIs were very low because potato fields were harvested or harvesting operation was going on in several fields. NDVI for all the fields followed similar pattern except field no. P03, P11 and P12. VIs at field P03, P11 and P12 attained its maximum value earlier then rest nine fields because of the early planting of potato. Conversely, saturation of VIs for these fields started during 15 Januray, 2018. The separation of VI values in early and late planted potato fields are apparent in GNDVI and NDI45 as observed in Figure 3 and 4 Inter field variability in VIs is also apparent which might be due to the variation in soil nutrients and moisture across the fields.

\subsection{Crop Monitoring in Spatio-Temporal Scale}

Spatio-temporal changes in crop dynamics were captured in vegetation indices maps. These maps are very useful analyzing spatial variability in crop growth with phenological developments. The standard false colour composite (FCC) of time-series Sentinel-2 images of the study area captures these variability well as observed in Figure 5
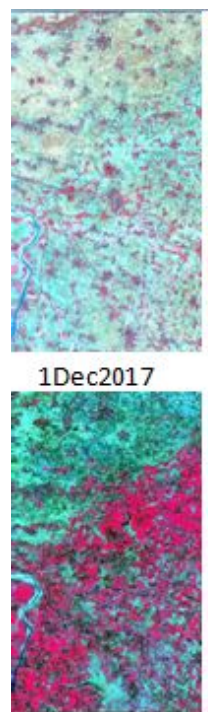

$25 \operatorname{Jan} 2018$
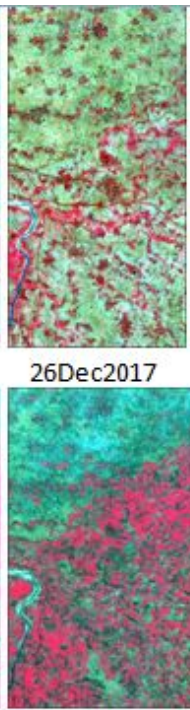

4Feb2018

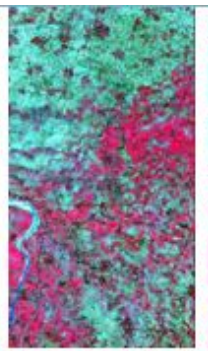

$10 \mathrm{Jan} 2018$

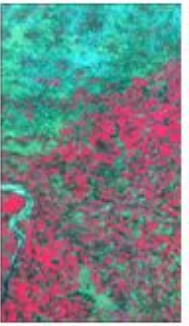

$19 F e b 2018$

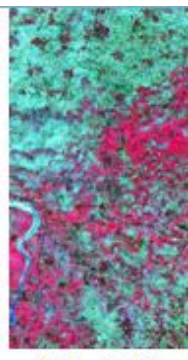

15Jan 2018

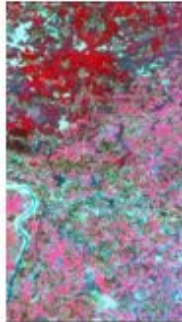

1March2018
Figure 5. Spatio-Temporal changes of vegetation in standard FCC (R:B8 G:B5 B:B4) of Sentinel-2.

Spatio-temporal variations in VIs during the crop season are shown in Figure 6, 7 and 8 The study area dominated by rice and potato cultivation. After harvesting the potato, paddy was 


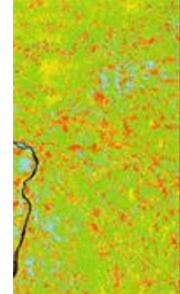

1Dec2017

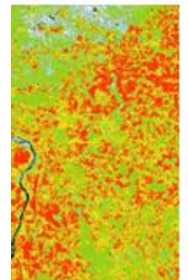

25Jan2018

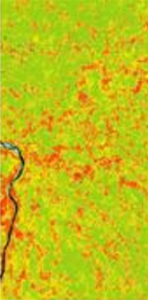

26Dec2017

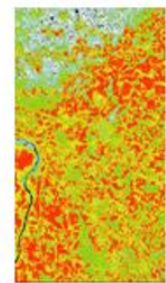

4Feb2018

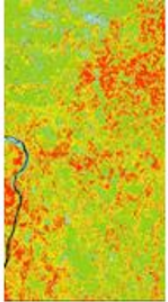

10Jan2018

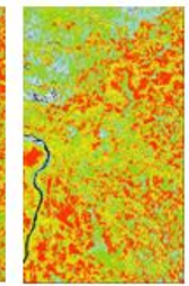

19Feb2018

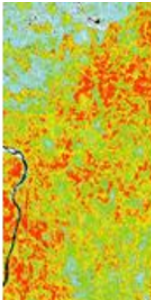

1.0

15Jan2018

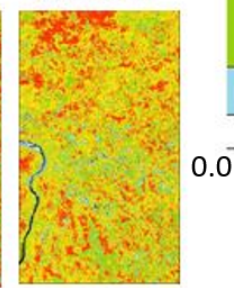

1March2018

Figure 6. Spatio-Temporal changes of NDVI in study area.

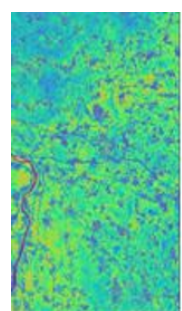

1Dec2017

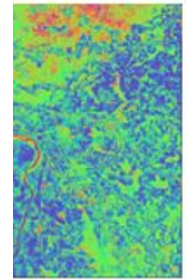

25Jan2018

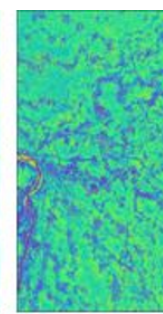

26Dec2017

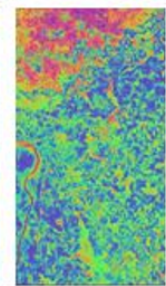

4Feb2018

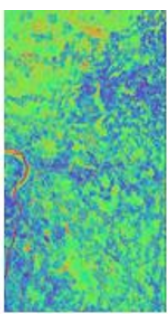

10Jan2018

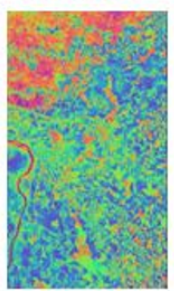

19Feb2018

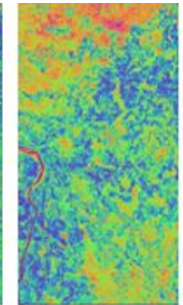

15Jan2018

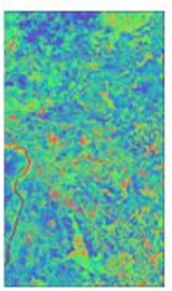

1March2018
1.0

0.0

Figure 7. Spatio-Temporal changes of GNDVI in study area.

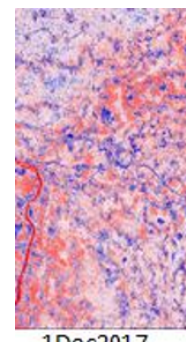

1Dec2017

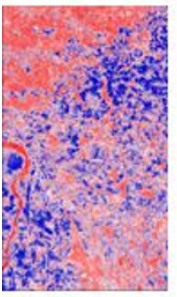

25Jan 2018
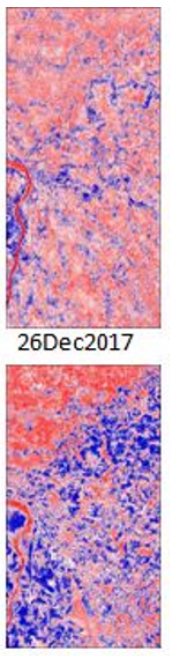

4Feb2018
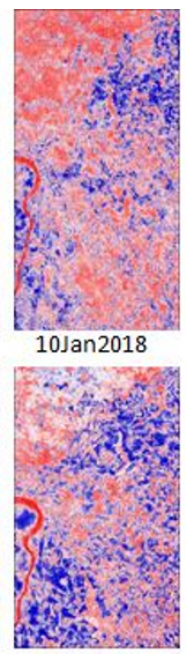

$19 F e b 2018$

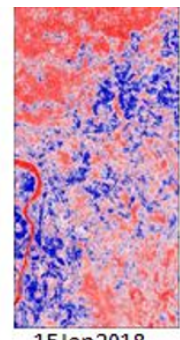

15Jan 2018

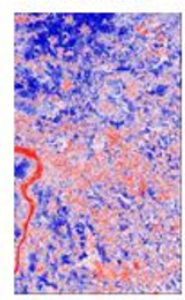

1March2018
0.5

0.0
Figure 8. Spatio-Temporal changes of NDI45 in study area. transplanted in several fields which is evident in the Figure 5 of 1 March,2018 (in upper left). However, the present study is only concentrated on potato. Dynamics of potato plants are in complete agreement with the time series trend of VIs. Dynamics of VIs with change in phenological stages of potato is apparent. Due to the competency of VIs for crop health monitoring, we analyzed the spatio-temporal changes of NDVI, GNDVI, and NDI45 for monitoring potato crop. Spatial extent of VIs were expanding with advancement of time. This pattern is likely due to increase in PAI and biomass as the plants were growing. Homogeneous pattern in spatial distribution of VIs indicated the homogeneity in plant health. It is evident from these maps that VIs can serves an a good proxy for tracking health condition of vegetation.

\subsection{Statistical Analysis of Vegetation Indices with Plant Bio- physical Parameters}

The correlation analysis of PAI and biomass of potato was performed to assess the capability of VIs for crop biophysical parameter retrieval as shown in Figure 9, 10 and 11 All VIs were positively correlated with both the biophysical parameters and had good correlation (Table 2).

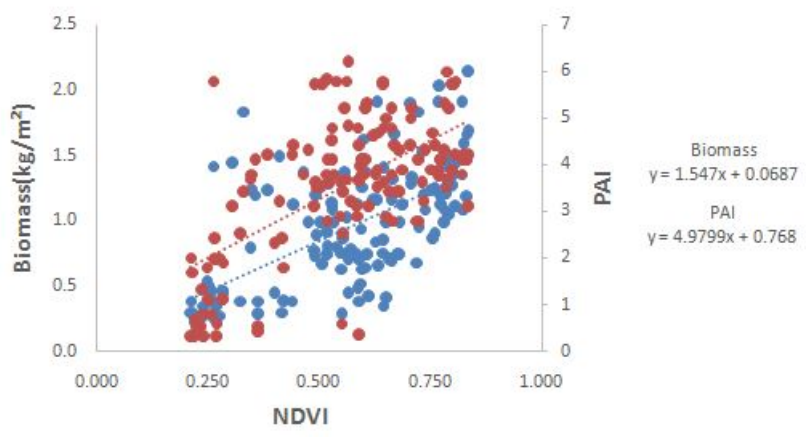

Figure 9. Statistical analysis of NDVI with PAI and biomass.

Table 2. Correlation coefficient (r) of crop biophysical parameters and VI

\begin{tabular}{|c|c|c|}
\hline Vegetation Index & Biomass & PAI \\
\hline NDVI & 0.611 & 0.620 \\
\hline GNDVI & 0.636 & 0.543 \\
\hline NDI45 & 0.572 & 0.585 \\
\hline
\end{tabular}

Among these VIs, GNDVI had highest correlation with biomass. Correlation coefficient of GNDVI for biomass was $2.5 \%$ higher as compare to that of NDVI. The higher correlation was the effect of replacing Green band with Red band in GNDVI formula because reflectance of Green band is caused by leaf structure. However, there was no improvement of correlation coefficient for NDVI45 over NDVI. Use of Red-Edge band instead of Near Infrared band did not yield into improvement in correlation for both the biophysical parameters. The correlation did not improved because red-edge bands are ideal for quantification of chlorophyll in plant but in this study we had consider the physical characteristic of plant not the biochemical aspect. NDVI had highest correlation with PAI.

\section{CONCLUSION}

In this study, a spatio-temporal analysis of vegetation indices derived from Sentinel-2 is performed for potato crop. The results of 


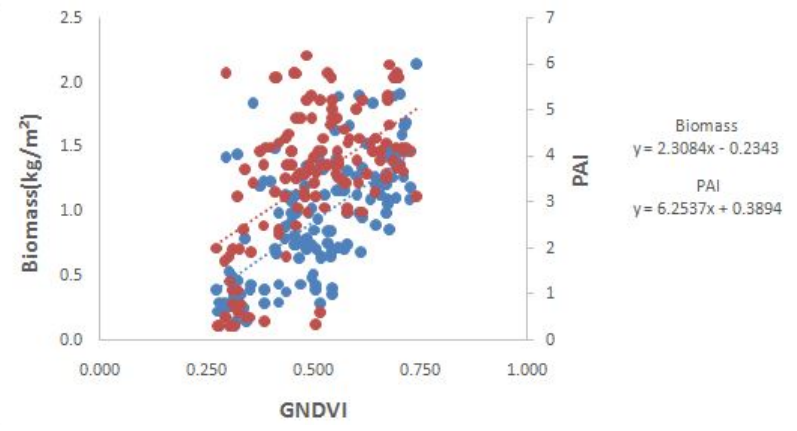

Figure 10. Statistical analysis of GNDVI with PAI and biomass.

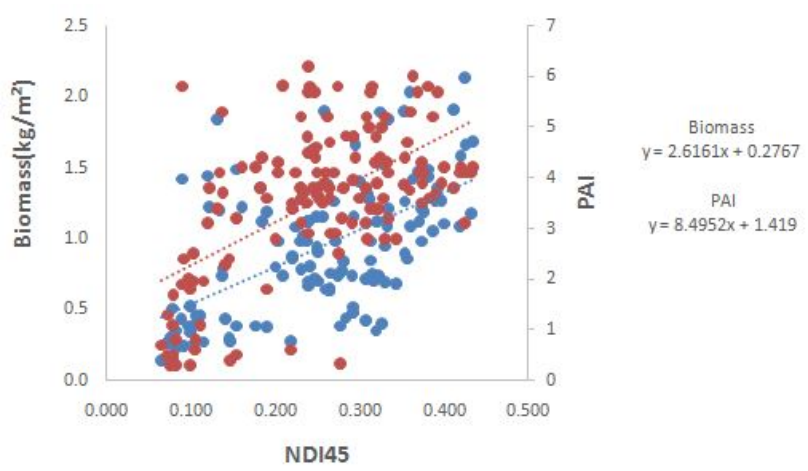

Figure 11. Statistical analysis of NDI45 with PAI and biomass.

time series analysis and correlation between biophysical parameters suggest that VIs can be aptly used for crop growth monitoring. Inter-field variation of VIs highlighted that crop monitoring in high spatio-temporal scale is required for generating real time warning and advisory to mitigate crop damage. It can help farmers in precisely locating the problem area in their field and run necessary field operation to mitigate loss in crop yield. Strong correlation of VIs with crop biophysical parameters assured that these indices can be used for tracking crop traits.

\section{ACKNOWLEDGEMENTS}

Authors would like to thank the European Space Agency for providing Sentinel-2 data through the Copernicus programme. The tremendous contribution of the field crew is also acknowledged. This research work is partially funded by ISRO sponsored project no. 17ISROC007.

\section{References}

Atzberger, C., 2013. Advances in remote sensing of agriculture: Context description, existing operational monitoring systems and major information needs. Remote Sensing 5(2), pp. 949981.

Baret, F. and Guyot, G., 1991. Potentials and limits of vegetation indices for LAI and APAR assessment. Remote sensing of environment 35(2-3), pp. 161-173.

Ceccato, P., Gobron, N., Flasse, S., Pinty, B. and Tarantola, S., 2002. Designing a spectral index to estimate vegetation water content from remote sensing data: Part 1: Theoretical approach. Remote sensing of environment 82(2-3), pp. 188-197.
Defourny, P., Sophie, B., Bellemans, N., Cosmin, C., Dedieu, G., Guzzonato, E., Hagolle, O., Inglada, J., Nicola, L., Rabaute, T. et al., 2018. Sentinel-2 near real-time agriculture monitoring at parcel level thanks to the Sen2-Agri automated system: methods and demonstration from local to national scale for cropping systems around the world. Remote Sensing of Environment.

Delegido, J., Verrelst, J., Alonso, L. and Moreno, J., 2011. Evaluation of Sentinel-2 red-edge bands for empirical estimation of green LAI and chlorophyll content. Sensors 11(7), pp. 7063 7081.

Frampton, W. J., Dash, J., Watmough, G. and Milton, E. J., 2013. Evaluating the capabilities of Sentinel-2 for quantitative estimation of biophysical variables in vegetation. ISPRS journal of photogrammetry and remote sensing 82, pp. 83-92.

Gitelson, A. A., Kaufman, Y. J. and Merzlyak, M. N., 1996. Use of a green channel in remote sensing of global vegetation from EOS-MODIS. Remote sensing of Environment 58(3), pp. 289298.

Haboudane, D., Miller, J. R., Tremblay, N., Zarco-Tejada, P. J. and Dextraze, L., 2002. Integrated narrow-band vegetation indices for prediction of crop chlorophyll content for application to precision agriculture. Remote sensing of environment 81(23), pp. 416-426.

Hansen, M. C. and Loveland, T. R., 2012. A review of large area monitoring of land cover change using Landsat data. Remote sensing of Environment 122, pp. 66-74.

Hazra, C., 2001. Crop diversification in India. Crop diversification in the Asia-Pacific Region.(Minas K. Papademetriou and Frank J. DentEds.). Food and Agriculture Organization ofthe United Nations. Regional Office for Asiaand the Pacific, Bangkok, Thailand pp. 32-50.

INRA, 2017. CAN-EYE. https://www6.paca.inra.fr/can-eye.

Jordan, C. F., 1969. Derivation of leaf-area index from quality of light on the forest floor. Ecology 50(4), pp. 663-666.

Mandal, D., Kumar, V., Bhattacharya, A., Rao, Y., S., Bera, S. and Nanda, M., K., 2017. Experimental Field Campaigns - Bardhaman Test Site. http://mrslab.in/FieldCampaign/TSBWN.

Mandal, D., Kumar, V., Bhattacharya, A., Rao, Y. S., Siqueira, P. and Bera, S., 2018. Sen4Rice: A Processing Chain for Differentiating Early and Late Transplanted Rice Using Time-Series Sentinel-1 SAR Data With Google Earth Engine. IEEE Geoscience and Remote Sensing Letters pp. 1-5.

Manjunatha, A., Anik, A. R., Speelman, S. and Nuppenau, E., 2013. Impact of land fragmentation, farm size, land ownership and crop diversity on profit and efficiency of irrigated farms in India. Land Use Policy 31, pp. 397-405.

Rouse, J., Haas, R., Schell, J. and Deering, D., 1974. Monitoring vegetation systems in the Great Plains with ERTS. In: Third ERTS Symposium, NASA SP-351, NASA, p. 309317.

Venkateswarlu, J., Ramakrishna, Y. and Rao, A., 1996. Agroclimatic zones of India. Annals of Arid Zone 35(1), pp. 1-7.

Whitcraft, A. K., Becker-Reshef, I. and Justice, C. O., 2015. A framework for defining spatially explicit earth observation requirements for a global agricultural monitoring initiative (GEOGLAM). Remote Sensing 7(2), pp. 1461-1481. 